\title{
Increasing the Efficiency of the Railway Operation in the Specialization of Directions for Freight and Passenger Transportation
}

\author{
Mykola Kurhan, Dmytro Kurhan, Marina Husak, \\ Nelya Hmelevska
}

Department of Transport Infrastructure, Dnipro National University of Railway

Transport named after Academician V. Lazaryan

Lazaryan st. 2, 49010 Dnipro, Ukraine

\{mykolakurhan, kurhan.d, marinahusak, hmelevnela\}@ diit.edu.ua

\begin{abstract}
It is shown that in the mixed traffic of trains compared to the directions specialized for transportation of freight and passengers, the traffic capacity is sharply reduced, and costs on repairs and maintenance of track infrastructure increase by 1.5-2 times. The paper outlines ways to solve the problem in the distribution of directions with mainly freight and passenger traffic to increase the traffic capacity of transportation on the rail network. Among the activities, there is the transmission of transit freight flow on parallel runs. Furthermore, changing the operation conditions of railways in the case of implementing the high-speed trains traffic requires strengthening the existing railway lines in the event of insufficient reserves.
\end{abstract}

Keywords: railway; high-speed trains; trains traffic; traffic capacity

\section{Introduction}

The topicality of the paper is defined by the need to address a rather complex problem in the distribution of directions with mainly freight and mainly passenger traffic and increase of the traffic capacity on the rail network. Domestic and foreign studies demonstrate that in the mixed traffic of trains compared to the directions specialized for transportation of freight and passengers, the traffic capacity and reliability in fulfillment of a schedule is sharply reduced and costs on repairs and maintenance of a railway track increase by 1.5-2 times. As a result, the transmission of transit freight flow on parallel runs is often used in practice. Consequently, it is necessary to reconstruct such directions for developing the freight flow that is being transmitted. The relevance of the research is also defined by changing the operating conditions of Ukrainian railways in the case of the 
high-speed trains traffic implementation, which requires strengthening the existing railway lines in the event of insufficient reserves.

In this regard, there is a need to substantiate, develop and implement the specialization of railway directions on the following principles:

- high-speed directions of passenger trains traffic;

- directions of intensive carrying capacity;

- directions of mixed traffic of passenger and freight trains.

The distribution of freight and passenger traffic is the main principle in organizing high-speed traffic in Europe. The analysis of contemporary publications shows that research on the choice of priority areas of international transportations include a wide range of issues, the main ones are:

- substantiation of logistics schemes of transportations, acceleration of the freight delivery time;

- increase in speed and traffic capacity;

- reduction of operating costs for current maintenance of infrastructure;

- research of the rolling stock/track interaction when changing the operating conditions.

\section{Review of the Literature}

Studies conducted on the Netherlands railways [1] consider the decision making issues faced by managers of the railway transport infrastructure in rail networks with dedicated tracks and corridors of public usage. The strategy upon consolidation of corridors, where the track serves passenger and freight trains is analysed. Various characteristics of passenger and freight trains are specified and the optimal distribution of tracks and consolidation time is analytically determined using two different patterns of models. The realistic parameters based on the Dutch railway system will be used in the experiments.

The optimization method for selecting a route for the everyday planning of freight trains is proposed in [2].

The mixed traffic of trains on the same tracks directly or indirectly affects the design, construction, operation, and maintenance of the railway system. In this context, the article [3] qualitatively and quantitatively evaluates the impact of some of the listed characteristics on the components of the rail system and presents the elements of the costs for the construction of the railway infrastructure, taking into account various exploitation scenarios. 
The choice of optimal transport decision includes the rationale of the most profitable routes, the choice of rolling stock in accordance with the type of freight, the freight transportation mode [4], the state of railway traffic safety [5], the influence of train velocity [6], the work technique of border stations [7, 8], etc.

In [9], models of decision making to evaluate the effectiveness of the transport system in Europe-Asia are presented and in [10], the model for the distribution of transit freight on the railway network is proposed.

Article [11] highlights theoretical foundations and empirical results of analyzing and modeling Poland's transport networks. Properties of complex networks (Scale Free and Small World) and network-specific parameters are described.

Work [12] considers applying the simulation model of the transport system in Poland as a tool for sustainable transport development and reasonably substantiate the scientific and technical use of rail transport in the international carriage.

Methods of research and solving current transport issues were considered at the International Scientific Conference Transportation of the 21st Century, June 9-12, 2019, Rin, Poland [13].

Most European countries successfully solve the problem of national passenger traffic based on a significant increase in the speed of trains on specially built lines [14].

The article [15] highlights the impact of existing speed limits of trains on the amount of additional energy on the haulage of trains. On the example of the Budapest-Kelenfold-Hegyeshalom line, the efficiency in removal of constraints of speed limits on the tracks is shown.

The evolution of high-quality express-passenger trains in Poland is described in [16], and in work [17], the driving mode of mixed multispeed freight trains with the distribution of passenger and freight transport is investigated.

When solving tasks with increasing the traffic and carrying capacity, the railway is considered as a holistic system consisting of devices and structures that due to the imperfect technical condition can restrict the speed of trains on one or another section. Therefore, for each barrier site on the railway, it is necessary to know the allowable speed of trains and parameters of devices according to which one needs to reconstruct the railway to realize these speeds [18].

It has been a considerable growth of freight and passenger transportation on the British railway network over the past 20 years [19], which raises concerns about its ability to absorb continued growth. A number of infrastructure initiatives aimed at increasing the traffic capacity and reducing conflicts were implemented. The impact of new railway infrastructure for the distribution of passenger and freight traffic on the operational characteristics of freight trains was studied. 
On the railways of North America [20,21], there is a rapid growth in demand for transportation, and a rise in traffic capacity is increasingly required to meet them. Non-uniformity in a combination of characteristics of various types of trains leads to more considerable delays than with uniform traffic. The analysis given in the work included the impact on the delay of various vehicles and the characteristics of trains. The simulation program of dispatching developed by the authors was used to analyze the model of a single-track line with characteristics typical for the railways of North America. The purpose was to determine the impact of various operating and infrastructure changes to reduce train delays. The reduction of delays was considered the advantage of the project for each scenario. In contrast, any increase in delays leads to the necessity of using additional locomotives and extra fuel consumption, increased costs for infrastructure maintenance.

North American railways experience a growth in demand for transportations, and increasingly require a rise in the traffic capacity of their lines, which requires changing a cycle process of operational work and modernization of infrastructure. In [22], it is shown that the expansion of infrastructure involves a long time and capital-intensive operations, and as an alternative, it is proposed to reach additional power by changing the operational work regime, which is often cheaper and faster in realization.

Article [23] presents a model of reliable freight routing in the intermedial network of automobile and rail transport. The model is aimed at providing an optimal route. The main contribution of this work is that a program of actions is provided, which allows you to determine the amount of reducing traffic capacity, which should be taken into account when planning routes to obtain a level of reliability specified by the user.

The implementation of large-scale investment projects (new construction, reconstruction of railways) that foresee high investment expenses and the need to include many factors entails the use of appropriate efficiency assessment methods. The following principles are the basis for evaluating the effectiveness of the project: consideration of an option (project) during the entire estimated period, positive and maximum effect, the consideration of time factor, the impact of inflation, uncertainty, risks, etc. The preliminary assessment is based on methods [24-26].

Years of research have proved that the most minor operating costs upon the maintenance of the railway track would be provided with the corresponding ratio of the load intensity of a track, the level of dynamic load on a track from the rolling stock, and the power of a railway track.

This principle is used in regulatory documents of Ukrzaliznytsia. For example, a category of a railway track is determined depending on the traffic density and from the governed speed of passenger and freight trains. In papers [27, 28], the load intensity of a track is also determined by traffic loading and the level of dynamic load on a track from rolling stock by the governed speed of trains. 
In [29], the railway track/rolling stock interaction results are presented under conditions of rapid and high-speed trains traffic.

In the existing rules of engineering of Hungarian railways, there are no design parameters for speeds exceeding $160 \mathrm{~km} / \mathrm{h}$. However, in the relevant international standard (ENV 13803), a similar speed limit is $300 \mathrm{~km} / \mathrm{h}$. The article [30] presents the results of comparing these rules.

A behavior pattern of the strain-stress state for the railway track based on the joint usage of propagation equations of an elastic wave to describe the topography of a part in the system involved in the interaction at a given moment of time, and equations of the dynamic equilibrium of its deformation are proposed in [31]. It enables to take into consideration the dynamics during the traffics of trains at high-speed.

\section{Methods and Results of the Research}

\subsection{Purpose of the Research}

Due to its geographical position and advanced transport infrastructure, Ukraine has significant potential in the development of international transportation, in particular as a transistor country in the logistics chain of trade between Asia and Europe [32]. However, in Ukraine, a classical form in the organization of traffic, which is to use infrastructure in the transportation of both passengers and freight (mixed traffic) has become an obstacle in the transition toward innovation-based development. The disadvantages of organizing such traffic are the insufficient comfort of passengers and the impossibility of using a new progressive rolling stock. A possible option for solving this problem is the separation of the freight traffic from the passenger one.

Problems of operational and technical nature arising during mixed traffic are primarily related to the disorders of the permanent way. When there is a changeover of the train flows to parallel runs, the traffic density of freight and passenger trains and other operational indicators change. These indicators affect the stress-strain state of a track and, consequently, on expenses associated with repair and maintenance of a track.

While dividing the freight and passenger transportation (even partly), the number of trains overtaking significantly reduces passenger and freight directions, leading to a decrease in operating expenses associated with braking, stops, and acceleration of trains. 
The first steps in this direction were made in Ukraine: a program has been developed, according to which freight flows should be evenly distributed in all directions, and not concentrated on the most heavy-traffic rail lines, for example, such as Kyiv-Dnipro. To that end, the secondary, so far little involved runs on which one can changeover the freight flows are put in a proper condition. Simultaneously, there are several operational and technical challenges associated with the ratio of speeds of freight and passenger trains, a decrease in trafficcarrying capacity of railways, where high-speed traffic is being introduced [14].

The purpose of the study is to develop mathematical models for the rational distribution of freight and passenger flows based on vector optimization to ensure a minimum of the indicator: car-mileage (train-km), time of traffic (train-hour), energy intensity (mechanical work of locomotives, tonne-kilometer, or electricity costs, $\mathrm{kWh}$ ), other technical and economic indicators.

\subsection{The Mathematical Model for the Rational Distribution of Train Flows}

To solve the problem of optimal distribution of train flows between the origin and destination, the network of railways was presented in the form of $G(V, E)$ graph, where stations are the graph vertex (set $V$ ), and sections between them - edges of graph (set $E$ ). Furthermore, the trains flow is given in a form of $P_{i j}$ matrix, $i, j=\overline{1, n}$, where $n$ is a number of stations, and $P_{i j}$ is a number of trains from point $i$ to point $j$ [33].

Considering that one can reach from one station to another in various ways, following the graph between points $i$ and $j$ there are $W_{i j}$ simple ways. Each edge $e \in E$ will be characterized by three parameters: edge length, train's traffic time on edge and mechanical work when driving a train on edge.

Let us denote a number of trains by $X_{i j w}$, moving from point $i$ to point $j$ along $w$-th simple route from list $W_{i j}$.

Then

$$
\exists w=\{e, v\}: \sum_{i=1}^{n-1} \sum_{j=i+1}^{n} \sum_{w \in W_{i j}} f(w) X_{i j w} \rightarrow \min ,
$$

where $f(w)$ is the total value of an indicator of the simple way $w$ from list $W_{i j}$.

The minimum value is determined with consideration to train flows, namely

$$
\begin{aligned}
& \sum_{w \in W_{i j}} X_{i j w}=P_{i j} ; \\
& i=\overline{1, n-1} ; i+1 \leq j \leq n .
\end{aligned}
$$


The limits upon the traffic capacity of each edge is added to these limits:

$\sum_{i=1}^{n-1} \sum_{j=i+1}^{n} \sum_{w \in W_{i j}} I_{w}(e) X_{i j w} \leq N(e)$,

where $N(e)$ is traffic capacity of edge $e$;

$I_{w}(e)$ is the edge indicator $e$ for the way $w$ :

$I_{w}(e)=\left\{\begin{array}{l}1, e \in w \\ 0, e \notin w .\end{array}\right.$

For example, Fig. 1 shows the optimization results by various indicators. One can consider multiple optimization indicators: train-kilometers $\left(f_{1}\right)$, train-hours $\left(f_{2}\right)$, mechanical work of a locomotive $\left(f_{3}\right)$. Thus, train-kilometers and ton-kilometers (gross) reflect railways' technical and freight work, train-hours is the average speed of the trains' traffic, and the mechanical work of the locomotive is the costs of electricity or diesel fuel.

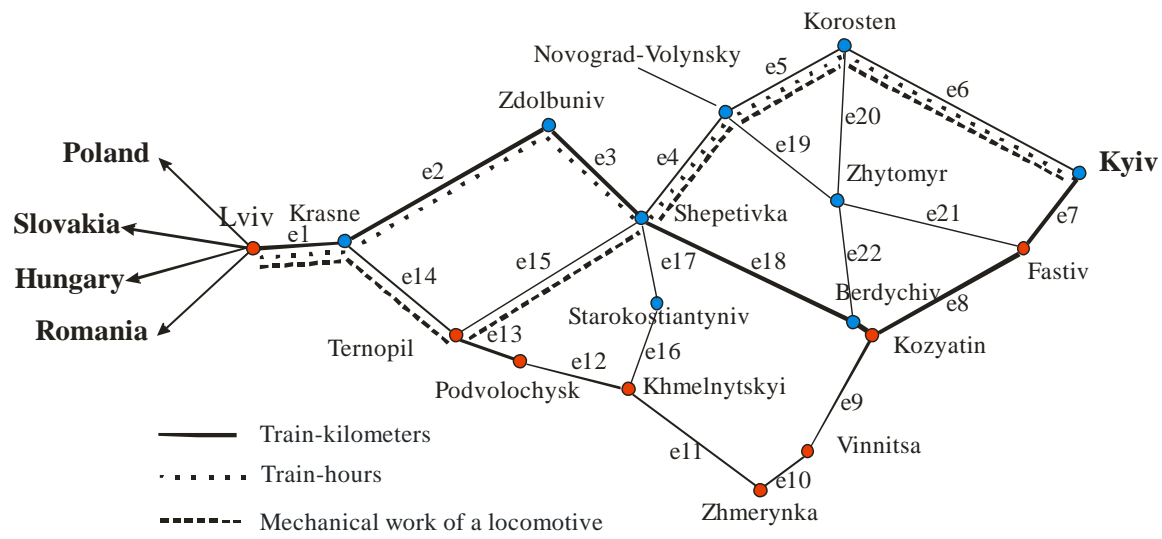

Figure 1

Distribution of trains between Kyiv-Lviv stations by different indicators of optimization

The final decision should be taken concerning the operating costs for the passage of freight and passenger trains, capital investments to enhance parallel runs, and the available opportunity in investing projects.

Therefore, further improvement of the transport process will be effective in the simultaneous specialization of railway directions. 


\subsection{Modeling the Trains Flow Traffic}

The approach offered by the authors is based on the alleged modeling of the trains flow traffic. The trains flow is presented in the form of a three-dimensional surface, which is an approximation for the real distribution of masses and speeds of trains.

The statistical data analysis showed that the distribution of motion speeds in one cross-section of the track for all trains of this type is approaching the normal law. While evaluating the deviations of empirical distribution from normal upon fitting criterion, it has been established that in most samples, these deviations are insignificant. In subsequent calculations, we can use theoretical distribution curves of actually implemented speeds.

When modeling the flow of trains, the standard deviation can be taken approximately such as before the reconstruction of the railway according to the results of the statistical processing of the speed recorder tapes. Calculations show that in most cases, the value of the standard deviation is $5-20 \mathrm{~km} / \mathrm{h}$.

When dividing the freight and passenger traffic, the directions will be set depending on the structure of the train flows: categories and masses of rotating trains, and motion speeds (Table 1).

On the sections of passenger and freight traffic, the working conditions of the track are improved due to the uniform load of both rail lines as an elevation of an outer rail in curves is set in accordance with the speed of passenger and freight trains, which leads to a decrease in the deterioration of track and rolling stock. The article [34] highlights the analysis results of the measurement parameters for the railroad track and the ratio of vertical and side wear of rails in curves of various radii under the different operating conditions. It is shown that the set elevations of the outer rail do not meet the current requirements of increasing the operability of the track when minimizing the wear of rails, and therefore dividing the freight and passenger traffic is a vital problem.

\subsection{Transmission of Freight Trains on Parallel Runs}

In the study of parallel runs, it is necessary to consider the technical condition of both railway directions. For example, a passenger run may be a single-track section or single-track with double-track inserts or double-track railways. In this case, the freight (parallel) run can also be in one of these technical states. Therefore, at least nine possible combinations occur.

There is a need to investigate the conditions under which the transfer of parts of freight traffic to the parallel run can be effective. The analysis showed that in the presence of parallel directions with two main tracks, there are almost no problems with the transfer of the train flow. The question is considerably more complex 
when one of the directions is single-track or with double-track inserts. The results of calculations for parallel directions represented by sections with double-track inserts are presented in the work. The basis of such an analysis can be the Program adopted by Ukrzaliznytsia concerning the increase of traffic capacity for sections with double-track inserts of Poltava-Kremenchuk-Burty-Korystivka-DolynskaMykolaiv due to the construction of the second main track.

Table 1

Classification of directions by categories of trains

\begin{tabular}{|c|c|c|}
\hline $\begin{array}{l}\text { Characteristics } \\
\text { of the direction }\end{array}$ & $\begin{array}{l}\text { Speed } \\
(V), \\
\mathrm{km} / \mathrm{h}\end{array}$ & Distribution graphs of trains speeds \\
\hline $\begin{array}{l}\text { High-speed } \\
\text { passenger } \\
\text { traffic: }\end{array}$ & $\begin{array}{l}V_{1} \in[160, \\
200] \\
V_{2} \in[120 \\
160] \\
V_{3} \in[100 \\
140]\end{array}$ & 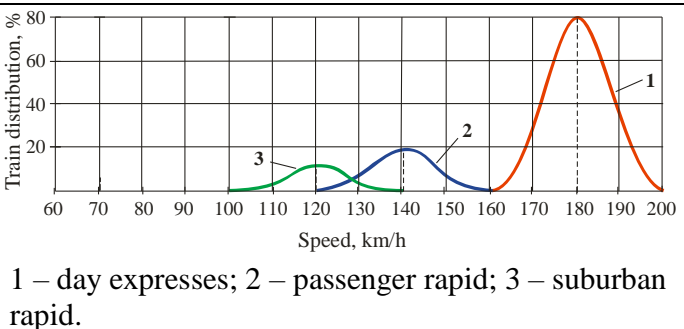 \\
\hline $\begin{array}{l}\text { Mixed traffic of } \\
\text { high-speed } \\
\text { passenger with } \\
\text { pickup freight } \\
\text { and suburban } \\
\text { trains: }\end{array}$ & $\begin{array}{l}V_{1} \in[160 \\
200] \\
V_{2} \in[90 \\
140] \\
V_{3} \in[80 \\
120] \\
V_{4} \in[60 \\
80]\end{array}$ & 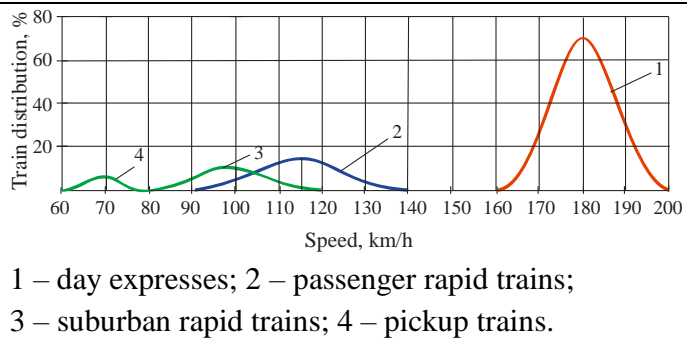 \\
\hline $\begin{array}{l}\text { Rapid passenger } \\
\text { traffic of trains } \\
\text { mixed with } \\
\text { rapid traffic of } \\
\text { suburban trains: }\end{array}$ & $\begin{array}{l}V_{1} \in[140, \\
160] \\
V_{2} \in[90, \\
140] \\
V_{3} \in[60, \\
80]\end{array}$ & 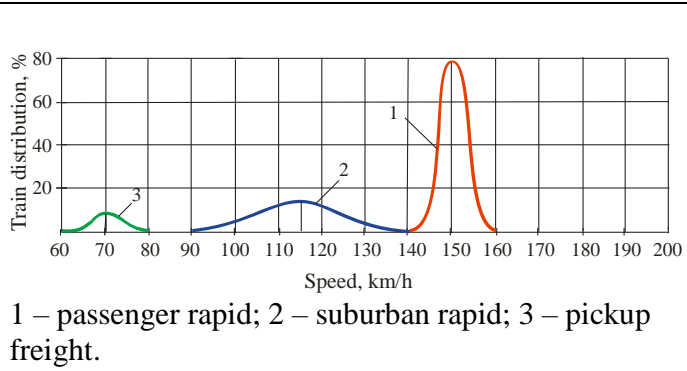 \\
\hline $\begin{array}{l}\text { A mixed traffic } \\
\text { of rapid } \\
\text { passenger trains } \\
\text { with pickup } \\
\text { freight and } \\
\text { suburban ones. }\end{array}$ & $\begin{array}{l}V_{1} \in[120, \\
160] \\
V_{2} \in[90, \\
140] \\
V_{3} \in[60, \\
80]\end{array}$ & 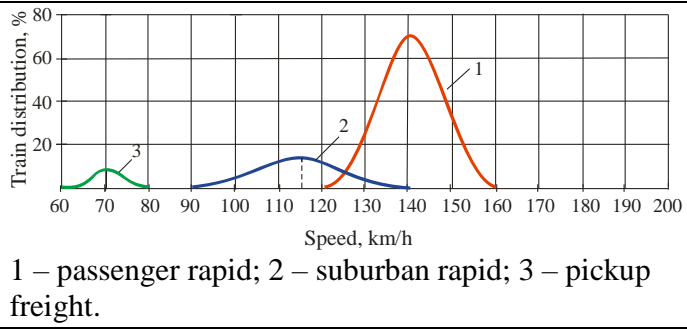 \\
\hline
\end{tabular}




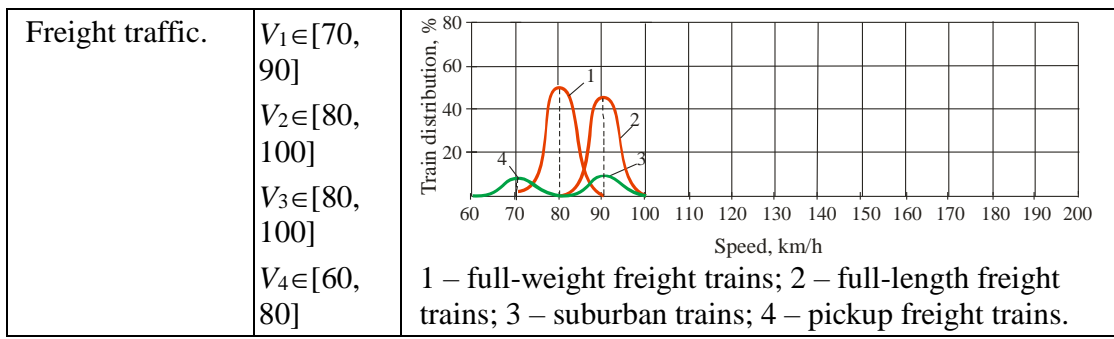

It was adopted that a parallel freight run has the same technical condition as a passenger one, and the necessary traffic density is changed by a linear law $G_{t}=G_{0}+\Delta G_{t}$. At the same time, three options were considered when the growth of traffic density occurs with different paces on a parallel run, namely $\Delta G_{t}=2 t, 3 t, 3.5 t$, at $G_{0}=5.0$ million nons / years.

From the graphs of traffic support (Figs. 3, 4) it is established, that with the available technical equipment and $G_{t}=5.0+4.5 t$ the railway will provide transportation till the 6th year of operation with the subsequent transition to a more powerful technical condition - the construction of the second track.

In the case of changeover, a part of freight $\Delta G_{t}$ on the parallel run the postponement of capital expenditures is achieved. The term in the postponement of the second track depends primarily on the value $\Delta G_{t}$. For example, when transferring 10 million tons/year on a parallel run, the construction of the second track is postponed till the $9^{\text {th }}$ year of operation; during the transfer of 20 million tons/year, postponing construction is possible till the $11^{\text {th }}$ year (Fig. 3).

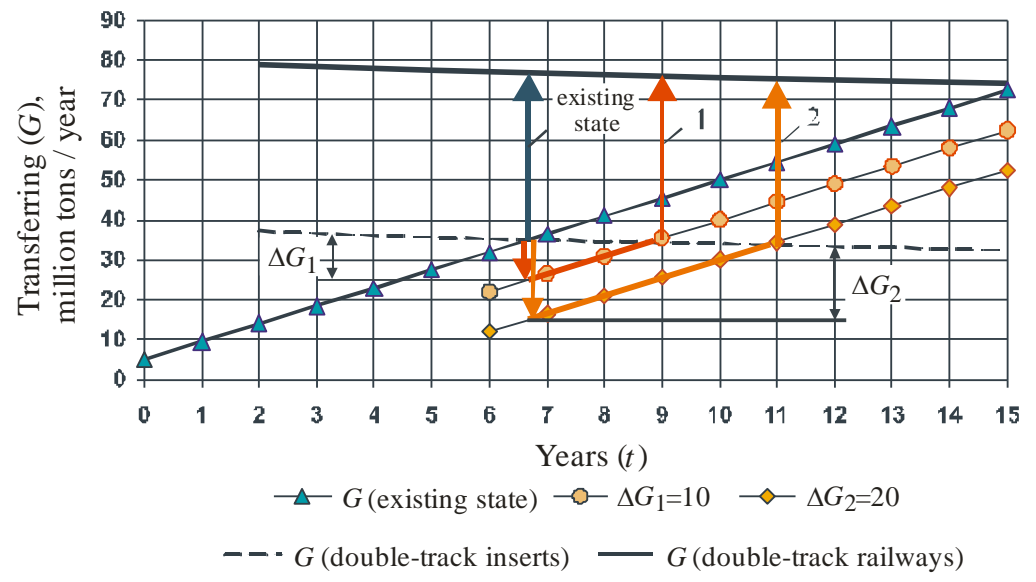

Figure 3

The graph of traffic support on a passenger direction when transferring 10 and 20 million tons/year on the parallel run 
With the growth of traffic density by law $G_{t}=5.0+2.0 t$ (the $1^{\text {st }}$ option) the parallel run can provide the necessary volumes of transportation until the $13^{\text {th }}$ year. When transferring freight flow in the $6^{\text {th }}$ year in a volume of 10 million tons/year, the reinforcement of the line will need to be performed in the $9^{\text {th }}$ year, during the transfer of 20 million tons/year - a line in the year of transferring the freight flow should be double-track (Fig. 4).

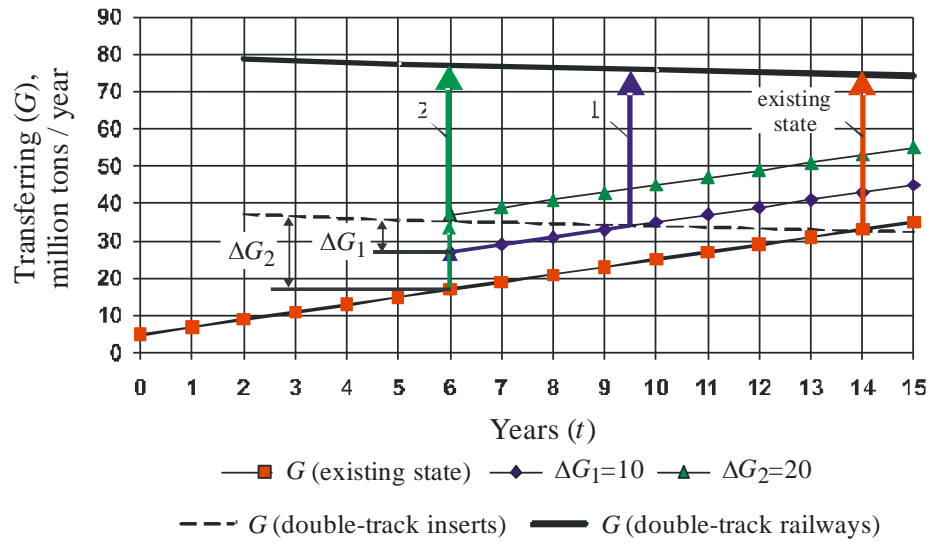

Figure 4

The graph of traffic support (freight traffic) on parallel run $G_{t}=5.0+2.0 t$

At other growth rates of traffic density (the $2^{\text {nd }}$ and the $3^{\text {rd }}$ options), the capacity of the parallel run is not enough, and therefore already in the $6^{\text {th }}$ year, the line needs to be reinforced by building a second main track.

\section{Conclusions}

1) The analysis of the technical equipment and parameters of the route for the main directions of international transport corridors passing through the territory of Ukraine, showed that it is impossible to meet European requirements, especially for the maximum speed of motion without dividing the freight and passenger traffic and restructuring the plan of a line. The results of the analysis confirm the timeliness of the work.

2) The classification of directions of railways by categories of trains and the structure of the train flow is specified and detailed. Five types of directions are proposed: purely passenger, mainly passenger, rapid, mixed, and freight traffic, which corresponds to the safety criteria, smoothness, and comfort of traveling.

3) Problems of operational and technical nature arising during mixed traffic, are primarily related to the disorders of the permanent way. When there is a changeover of the train flows to parallel runs, the traffic density of freight and passenger trains and other operational parameters change. These parameters affect the stress-strain state of a track and, consequently, on expenses associated with repair and maintenance of a track. 
4) In the dividing freight and passenger traffic, the total effect in each direction should be determined separately. On the sections of passenger and freight traffic, the working conditions of the track are improved due to the uniform load of both rail lines as an elevation of an outer rail in curves is set in accordance with the speed of passenger and freight trains, which leads to a decrease in the deterioration of track and rolling stock.

5) The number of trains overtaking significantly reduces passenger and freight directions, leading to a decrease in operating expenses associated with braking, stops, and acceleration of trains. In addition, it allows receiving additional profits by reducing the track disorder.

6) The proposed approach makes it possible to consider the opportunity to transfer the part of trains on parallel runs and evaluate the profit by dividing the freight and passenger traffic. The mathematical model of mixed formation for the scheme of traffic support for parallel railway lines makes it possible to take into consideration the specifics of each from the parallel directions (passenger, freight, mixed traffic) and obtain problem solving with minimal operating costs and rational investments, including reorganization of the railway to increase. The speed of passenger trains.

\section{References}

[1] E. Ursavas, Stuart X. Zhu. Integrated Passenger and Freight Train Planning on Shared-Use Corridors. Transportation Science, Vol. 52(6), 2018, pp. 1297-1588

[2] S. Li, H. Lv, C. Xu, T. Chen, C. Zou. Optimized Train Path Selection Method for Daily Freight Train Scheduling. IEEE Access, Vol. 8, 2020, pp. 40777-40790

[3] C. Pyrgidis, E. Christogiannis. The Problems of the Presence of Passenger and Freight Trains on the Same Track. Procedia - Social and Behavioral Sciences, Vol. 48, 2012, pp. 1143-1154

[4] A. Shvets. Dynamic Indicators Influencing Design Solution for Modernization of the Freight Rolling Stock. FME Transactions, Vol. 49(3), 2021, pp. 673-683

[5] A. Blagojevic, Ž. Stevic, D. Marinkovic, S. Kasalica1, S. Rajilic. A Novel Entropy-Fuzzy PIPRECIA-DEA Model forSafety Evaluation of Railway Traffic. Symmetry, Vol. 12(9), 2020, 1479

[6] V. Kovalchuk, M. Sysyn, U. Gerber, O. Nabochenko, J. Zarour, S. Dehne. Experimental investigation of the influence of train velocity and travel direction on the dynamic behavior of stiff common crossings. Facta universitatis - series Architecture and Civil Engineering, Vol. 17(3), 2019, pp. 345-356

[7] N. Chornopyska, K. Stasiuk. Logistics Potential of the Railway as a Key for Sustainable and Secure Transport Development. Transport Means, 2020, pp. 421-425 
[8] M. Kurhan, D. Kurhan, L. Černiauskaite. Rationale of priority areas of rail operation in north-eastern Europe. Transport Means, 2019. pp. 1439-1444

[9] M. Szkoda, A. Tulecki. Decision Models in Effectiveness Evaluation of Europe-Asia Transportation Systems. 8th World Congress on Railway Research, Seoul, Korea, 2008

[10] D. Kozachenko, V. Skalozub, B. Gera, Y. Hermaniuk, R. Korobiova, A Gorbova. A model of transit freight distribution on a railway network. Transport Problems, Vol. 14(3), 2019, pp. 17-26

[11] Z. Tarapata. Modelling and analysis of transportation networks using complex networks: Poland case study. The Archives of Transport, Vol. 36(4), 2015, pp. 55-65

[12] M. Jacyna, M. Wasiak, K. Lewczuk, M. Kłodawski. Simulation model of transport system of poland as a tool for developing sustainable transport. Archives of Transport, Vol. 31(3), 2015, pp. 23-35

[13] M. Siergiejczyk, K. Krzykowska. Research Methods and Solutions to Current Transport Problems. Proceedings of the International Scientific Conference Transport of the $21^{\text {st }}$ Century, Ryn, Poland, 2019

[14] A. Németh, S. Fischer. Investigation of glued insulated rail joints applied to CWR tracks. Facta Universitatis Series Mechanical Engineering, 2021, 7642

[15] S. Fischer. Traction Energy Consumption of Electric Locomotives and Electric Multiple Units at Speed Restrictions. Acta Technica Jaurinensis, Vol. 8(3), 2015, pp. 240-256

[16] A. Massel. Train Commercial Speed Versus Maximum Line Speed Central-European Experience. Transport Means, 2019, pp. 358-366

[17] H. Zhipeng, N. Huimin. The Mode of Combined Multi-speed Freight Trains under Separation of Passenger and Freight Transport. Procedia Social and Behavioral Sciences, Vol. 43, 2012, pp. 709-717

[18] R. Pittman. Reforming and restructuring Ukrzaliznytsia: a crucial task for Ukrainian reformers. Science and Transport Progress, Vol. 1(67), 2017, pp. $34-50$

[19] A. Woodburn. The impacts on freight train operational performance of new rail infrastructure to segregate passenger and freight traffic. Journal of Transport Geography, Vol. 58, 2017, pp. 176-185

[20] M. H. Dingler, Y-C. (Rex) Lai, C.P.L. Barkan. Impact of Train Type Heterogeneity on Single-Track Railway Capacity. Transportation Research Record, Vol. 2117(1), 2009, pp. 41-49

[21] M. H. Dingler, Y-C. (Rex) Lai, C. P. L. Barkan. Mitigating train-type heterogeneity on a single-track line. Proceedings of the Institution of 
Mechanical Engineers, Part F: Journal of Rail and Rapid Transit, Vol. 227(2), 2013, pp. 140-147

[22] Y-C. (Rex) Lai, Y-J. Lin, Y-F. Cheng. Assessment of Capacity Charges for Shared-Use Rail Lines. Transportation Research Record, Vol. 2448(1), 2014, pp. 62-70

[23] M. Uddin, N. Huynh. Reliable Routing of Road-Rail Intermodal Freight under Uncertainty. Netw Spat Econ, Vol. 19, 2019, pp. 929-952

[24] Guide to Cost-Benefit Analysis of Investment Projects. https://ec.europa.eu/regional_policy/sources/docgener/studies/pdf/cba_guid e.pdf [online, last visited on: 2019.09.11]

[25] Dac Criteria for Evaluating Development Assistance https://www.oecd.org/dac/evaluation/49756382.pdf [online, last visited on: 2019.09.11]

[26] Results-Based Management approach as applied at UNESCO https://unesdoc.unesco.org/ark:/48223/pf0000177568 [online, last visited on: 2019.09.11]

[27] B. Leitner, D. Rehak, R. Kersys. The new procedure for identification of infrastructure elements significance in sub-sector railway transport. Communications - Scientific Letters of the University of Zilina, Vol. 20(2), 2018, pp. 41-48

[28] G. Bureika, L. Bielousova, V. Nozhenko. Estimation of Ecological Effectiveness of Rail Vehicle Operation in Eurasian Railway Corridors. Transport Means, 2019, pp. 460-465

[29] O. Hubar, R. Markul, O. Tiutkin, V. Andrieiev, M. Arbuzov, O. Kovalchuk. Study of the interaction of the railway track and the rolling stock under conditions of accelerated movement. IOP Conf. Ser.: Materials Science and Engineering, Vol. 985, 2020, 012007

[30] S. Fischer. Comparison of railway track transition curves. Pollack Periodica, Vol. 4(3), 2009, pp. 99-110

[31] D. Kurhan, M. Kurhan Modeling the Dynamic Response of Railway Track. IOP Conf. Ser.: Materials Science and Engineering. Vol. 708, 2019, 012013

[32] M. Kurhan, D. Kurhan. The effectiveness evaluation of international railway transportation in the direction of "Ukraine - European Union", Transport Means, 2018, pp. 145-150

[33] D. M. Kurgan, M. A. Zayats. The definition of rational allocation of trainflows on the rail network. Science and Transport Progress, Vol. 34, 2010, pp. 88-93

[34] M. Kurhan, D. Kurhan, R. Novik, S. Baydak, N. Hmelevska. Improvement of the railway track efficiency by minimizing the rail wear in curves. IOP Conf. Ser.: Materials Science and Engineering, Vol. 985, 2020, 165475 